\title{
Reply to Colin Marshall and Martin Lin
}

\section{Yitzhak Melamed, Johns Hopkins University}

1. Let me begin by thanking my two critics for the thought and time invested

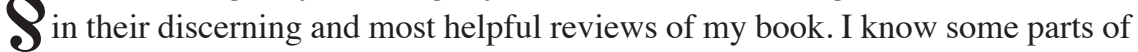
it are quite technical and demanding, and I am grateful for the close attention they dedicated to the work. I feel honored and fortunate to have had these two minds study the book so closely. Both critics raise a number of important points that lead us into what I believe are some of the deepest and most foundational issues in Spinoza's metaphysics. In the following I will respond to my critics, following the order of their comments. I will mostly avoid summarizing the book, since my critics have performed this task (almost) impeccably (though I will note the one or two cases in which my views have been slightly misunderstood). I will attempt to address most, if not all, of the major points raised, though obviously the discussion of each issue will have to be restricted. On most issues, my response will begin in medias res in order to avoid redundancy; the reader is invited to consult the objection to which I respond. I will mostly avoid discussing the many points on which we agree, since it is precisely the contended issues which I believe can help us make progress toward understanding Spinoza's surprising and frequently dense claims.

\$2. God or the Most General Principle of Order. - The first chapter of my book defends the view that for Spinoza the relation of being in another [in alio] (or in itself [in se]) is a genuine inherence relation, and not merely a causal relation, as Edwin Curley has famously argued. ${ }^{1}$ For Curley, Spinoza's claim "what is, is in God" (E1p15) amounts to nothing more than the claim that God is the cause of all things. Addressing my arguments against Curley's interpretation, Marshall writes, "I think that Melamed is right that we have ample reason to deny that Spinoza understood the inherence of modes in substance to just be an instance of efficient causation, and that Melamed has some textual basis for taking Curley to advance such a view (though Curley never states his view in terms of efficient causation). At the same time, I think Melamed's criticisms miss the most plausible and important aspect of Curley's reading, which identifies God with 'the most general principles of order exemplified by things' (Curley [1988], 42). The relationship between a principle of order and a thing that exemplifies it is not one of efficient causation, though, like efficient causation, it can be understood as a sort of asymmetric dependence" [188-89].

The Leibniz Review, Vol. 23, 2013 
Let me first explain why I rendered Curley's interpretation in terms of efficient causation. The reason is simple. Spinoza explicitly claims that "God is the efficient cause of all things" (E1p16c1), and he never claims that any other kind of causation obtains between natura naturans and natura naturata. Spinoza's elucidation of the notions of immanent and transitive causes in E1p18d shows clearly that he understands the two as species of the efficient cause (a claim Spinoza also explicitly states in the Short Treatise ${ }^{2}$ ). In light of this textual evidence, I see no reason to assume that the causation at stake is not efficient causation. ${ }^{3}$

Now, let us turn to Curley's view of God as "the most general principle of order." Marshall is absolutely right that I addressed this aspect of Curley's interpretation only briefly (See Melamed [2013], 11-12). I did so because I found it the least plausible aspect of Curley's argument (as I explained in Melamed [2013], 12). This is another instance of the misuse of the principle of charity (on my part, this time), and I am grateful to Marshall for providing the opportunity to fill this lacuna. There are several substantial considerations against interpreting Spinoza's God as "the most general principle of order."

First, Spinoza ascribes to God a number of crucial qualities which I cannot imagine applying to "the most general principle of order." Consider, for example, the quality of having an essence involving existence (E1p11 and E1p20). What would it mean for a principle to have an essence involving existence? We may agree that "the most general principle of order" should be self-conceived; but in addition to claiming that God is self-conceived, Spinoza also proves that God's essence involves existence. I, for one, cannot make sense of the claim that a principle could have such an essence. Similarly, consider the qualities of indivisibility (E1p13), of being most real (E1p10s), and of having the power to exist (E1p11d). In what sense could these be ascribed to a principle?

Second, Spinoza is clearly familiar with the term principle [principium], and he employs it quite frequently both in the Ethics and elsewhere. However, nowhere in the Ethics - or, as far I can tell, in any other text - does he make a claim that seems to support the identification of God with a principle. Why then should we ascribe to Spinoza a claim which could easily have been formulated in the terminology that was available to him, and which he nevertheless showed not even the slightest inclination to develop?

Third, Spinoza defines God as a substance (E1d5), and a substance - in early modern terminology, as in our own - is a thing [res]. Furthermore, Spinoza frequently refers to God as res extensa or res cogitans. Why would he systematically

The Leibniz Review, Vol. 23, 2013 
mislead his readers by always referring to God as res (or substantia), and never as principium, if he indeed thought that God is a "principle of order"?

Fourth, within Spinoza's system, the notion closest to "the most general principles of order" is, as far as I can see, the notion of eternal truth [veritas aeterna]. Spinoza discusses eternal truths quite frequently. Yet, he never suggests an identification of God, or the substance, with an eternal truth. ${ }^{4}$

The bottom line of all these points is that Spinoza's text leaves little if any doubt that he conceives God as an entity (being a substance, having a certain degree of reality, being either divisible or indivisible, etc.), rather than a principle of order or a law of nature.

§3. Hegel's Complaint. - Addressing my response to Hegel's critique of Spinoza for failing to derive the modes from the substance, Marshall objects that I seem to have missed Hegel's main point. I argued that for Spinoza modes are derived from God's essence, i.e., they follow from God's essence qua God's propria (Melamed [2013], 70-71). In response, Marshall writes: "stating that $\mathrm{y}$ is derived from $\mathrm{x}$ is not the same thing as providing a derivation of $\mathrm{y}$ from $\mathrm{x}$, and it seems to be the latter that Hegel is concerned with" [190].

This is an important and perceptive objection. However, let us have a closer look at Hegel's actual complaint: "Absolute substance, attribute and mode, Spinoza allows to follow one another as definitions; he adopts them ready-made, without the attributes being developed from the substance, or the modes from the attributes." 5 Hegel presents substance, attributes, and modes in a descending hierarchy, almost as in theories of emanation. This presentation is erroneous, since the attributes are not "developed from" the substance (for Spinoza, there is not, and cannot be, an attributes-free substance, from which the attributes could develop as a second, Hegelian, moment). Yet, this is merely a side issue. The main question is what kind of development Hegel has in mind here. If it is a development of the categories of attributes and modes, then Spinoza parts ways with Hegel at the very moment this demand is formulated. The categories of attributes and modes are mere universals or entia rationis for Spinoza, and as such they are explicated through his theory of the human mind (see E2p40s2). What truly follows from God's essence are the concrete modes (not the category of modes). Hegel and Marshall are right that all that Spinoza offers is a proof that the modes follow from God's essence (E1p16d). Spinoza does not show how a specific mode (for example, my mind or my left shoe) follows from God's essence. Yet, as far I can see, Hegel too does not explain, or even attempt to explain, how individual things (such as my mind or

The Leibniz, Review, Vol. 23, 2013 
my left shoe) follow from his notion of the absolute. ${ }^{6}$ Both philosophers seem to relegate the study of the specific causes of a particular thing to the relevant branch of the sciences, rather than to metaphysics or ontology.

§4. "Illusory." - I very much like the "illusory cat" counterexample which Marshall offers [190-91], yet I suspect that he and I may have different criteria for what constitutes an illusion. Hegel's argument for the illusory nature of modes seems to be roughly the following: (1) Modes have no reality of their own (a premise Spinoza would clearly accept). (2) Spinoza fails to derive the modes from the substance (premise). Hence, (3) Spinoza's modes are detached from the substance (relying on (2)). Hence, (4) Spinoza's modes are not real, or in other words, they are illusory, since they cannot derive their reality from the substance (relying on (1) and (3) (See Melamed [2013], 66-70). The element common to the five arguments I presented against Hegel's acosmist reading of Spinoza (Melamed [2013], 79-82) is that they all show that modes are part of the causal web of nature which is ultimately grounded in God's essence. Thus, these arguments show that (2) is wrong and that the modes are not detached from God. In other words, the modes can be fully real insofar as they are well grounded in the substance. Of course, there could be other arguments against the reality of modes, but the argument at stake is Hegel's, and I have attempted to show that his quite influential argument against the reality of modes fails. ${ }^{8}$

§5. "The Mysteries of Inherence." - Addressing my arguments against Michael Della Rocca's identification of inherence, causation, and conceivability, Marshall writes: "The mere fact that a reading attributes to Spinoza an unorthodox view is not much of a point against it by itself" [191]. So far, I fully agree. Marshall continues: "After all, the core of Della Rocca>s proposal is that three prima facie distinct properties end up being identified. For that reason, we should expect there to be surprising implications. Moreover, inherence is perhaps more metaphysically mysterious than causation, so collapsing the former (even with some surprising implications) into the latter carries some philosophical virtues" [191-92]. I have no qualms about ascribing bold and counter-common sense claims to Spinoza, both because Spinoza himself does not shy away from such claims and because I find well-motivated counter-common sense arguments most profitable for initiating foundational investigations. This, however, does not imply an "anything goes" attitude: any unorthodox view ascribed to Spinoza should be documented in his text, and should not conflict with his other key claims.

The arguments that Marshall takes issue with attempt to establish that Della

The Leibniz Review, Vol. 23, 2013 
Rocca's one inherence-causation-conception relation has all the characteristics of a genuine causal relation, and virtually none of the characteristics of inherence. Thus, I concluded, it is a misnomer to call this relation "inherence." In one instance of this line of argumentation, I argued that, for Spinoza, what inheres in another is less real than its substratum (since its existence depends on the existence of its substratum). Now, if we accept Della Rocca's identification of inherence and causation, it seems that Spinoza would have to be committed to the view that the past is more real than the present (since the past is the cause and thus - by virtue of the inherence-causation identity - the substrate of the present). The view that the past is more real than the present is indeed mysterious and surprising, but this is not at all the consideration which should lead us to reject the view. Rather, we should reject it as a legitimate interpretation of Spinoza because I see no evidence in Spinoza's text that grants such ontological priority to the past, and because, as far as I can see, Spinoza is committed to the view that all times are equally real (E4p62).

\$6. Bifurcations. - Marshall aptly summarizes my argument as showing that within Spinoza's metaphysics there is a series of genuine bifurcations: between immanent and transitive causation, between eternity and duration, between conceiving a thing under an attribute and conceiving it through its cause, and ultimately, between substance and mode. I also argue that Della Rocca cannot avoid these (and similar) bifurcations, and that they are not brute (as Della Rocca argues) but rather grounded in the foundational bifurcation between substance and mode. My arguments against Della Rocca's position led Marshall to conclude that "Melamed thinks that Della Rocca has to accept more bifurcations than he does." I do not. I simply think that Della Rocca cannot avoid these bifurcations, and that any attempt to efface one bifurcation is likely to result in the creation of another. I raised the issue of the bifurcations in order to show (1) that Della Rocca cannot avoid them, and (2) that they are all grounded in the dichotomy between substance and mode, and thus, pace Della Rocca, are not brute.

\$7. One Substance, One Mode.-At the end of his discussion of my third chapter, Marshall raises a nice objection, claiming that we can conceive and make sense of a Spinozist world in which the substance has only one mode. In such a world, claims Marshall, we will have only immanent, but not transitive, causation, and thus it would seem that the substance/mode bifurcation (which obtains in the suggested world) does not suffice to explain the immanent/transitive cause bifurcation (which does not obtain in said world).

The Leibniz, Review, Vol. 23, 2013 
This is a fine objection, yet, upon further consideration, I believe transitive causation must obtain in Marshall's world as well. Here is a rough outline of the considerations leading to this conclusion. We have good textual evidence showing that, for Spinoza, modes, as opposed to substance, are divisible (See Melamed [2013], 126-136). Thus, our one mode - call it ' $M$ ' - must be divisible. We also know that for Spinoza a thing is said to be composed of parts to the extent that the parts must "adapt themselves to one another." 9 This mutual adaptation, or interaction, among the parts of $\mathrm{M}$ is a causal relation which does not involve inherence, since the dependence between the parts of $\mathrm{M}$ is symmetric, while the in alio inherence relation is asymmetric. ${ }^{10}$ Thus, the causal relation among the parts of $\mathbf{M}$, our one mode, must be one of transitive causation.

§8. One Simple Cause, One Effect. - In my chapter on the infinite modes (ch.4), I attempted to reconstruct the general characteristics of Spinoza's infinite modes (regardless of the attribute to which they belong). By looking closely at his difficult argument in E1p21d, I believe that I am able to recover a feature of the infinite modes which has barely been observed in the existing literature. In this text Spinoza seems to be arguing that only one infinite mode can follow (immediately) from God's essence. Spinoza justifies this non-trivial point by claiming that, otherwise, none of the two or more immediate infinite modes which are said to follow from God's essence would follow necessarily. ${ }^{11}$ Initially, I was quite perplexed by this last claim. Why would the flow of more than one (immediate) infinite mode contradict the necessity of this flow? Upon further reflection, I thought I could explain this claim through a corollary of the Principle of Sufficient Reason (henceforth, PSR). Much of my explanation addressed the details of Spinoza's text in E1p21d. This may well have made it difficult to follow the argument, as Marshall justly notes. In the following, I will attempt to explain briefly Spinoza's reasoning in denying that God's essence could cause more than one immediate infinite mode, concentrating on the argument rather than the text (for an analysis of the text of E1p21d, see Melamed [2013], 116-119).

We should note first that God's essence is simple, i.e., it has no parts. Now, let us assume that God's essence causes two distinct things, A and B. Relying on the PSR, Spinoza would ask what explains the difference between A and B. Since it is given that the cause of A is merely God's essence, and that the cause of B is merely God's essence, there seems to be no possible explanation for the difference between $\mathrm{A}$ and $\mathrm{B}$.

Marshall suggests a simple and helpful counterexample: "Consider a flat-footed

The Leibniz Review, Vol. 23, 2013 
example: Volcan 2 hecessarily cause both tremors and smoke, and tremors and smoke are distinct." Here, Marshall claims, we have a trivial example of one cause bringing about two distinct effects. Spinoza, I believe, would have little problem with this example, since the cause in this case - the volcano - is not simple. A volcano has numerous parts, and thus, the Spinozist would argue, there are distinct parts or elements in the volcano that cause the tremor and the smoke. In our daily experience we seldom encounter simple entities, and thus we imagine that we frequently encounter cases where one cause brings about several effects; however, the Spinozist would argue, in all these cases the relevant cause is an aggregate, and distinct parts of the aggregate cause the distinct effects.

In order to prove that only one effect can follow from one (simple) cause, the Spinozist might also begin with Hume's "same cause, same effect" principle: "The same cause always produces the same effect, and the same effect never arises but from the same cause. This principle we derive from experience and is the source of most of our philosophical reasoning." 12 We might have various qualms about different aspects or formulations of this principle, but we need it, as Hume suggests, if we are to engage in scientific or philosophical reasoning. Indeed, it is highly questionable whether we could have any intelligible experience at all without it. Now, Hume's principle refers to cases where the same (or a perfectly similar) cause obtains at different times. Hume seems to take his principle as brute (i.e., learned from experience, rather than derivable from a more basic principle or reason). Unlike Hume, the Spinozist can appeal to the PSR and argue that, if the same (simple) cause should result in different effects (either at the same time or at different times), the difference between the effects would be unexplainable. This last claim - that one and the same (simple) cause can have only one effect - seems to be the link between the PSR and Hume's principle, i.e., it can motivate Hume's principle, and is itself motivated by the PSR. I suspect that it is precisely this link that is doing the explanatory work in E1p21d.

In recent correspondence, Marshall has raised another important objection. The infinitely many attributes are said to express God's essence (E1d6). Marshall rightly notes that expression (in E1d6) is not a causal relation. Still, he wonders how God's simple essence could be expressed by a multiplicity of things. In response, let me first admit that I consider the elucidation of Spinoza's notion of expression to be one of the major desiderata of current Spinoza scholarship. Second, let me point out that the relation of expression seems to violate the PSR in an even more trivial manner, since each of the infinitely many attributes is supposed to fully express

The Leibniz, Review, Vol. 23, 2013

\section{3}


God's essence. I take this point as further evidence that the relation of expression at stake is not a causal relation. I consider the attributes to be different aspects of God's essence (see Melamed [2013] xix-xx, 83-86, and 155-6 for an explanation of 'aspect'), and if we consider the relation of expression in E1d6 to be merely a relation of being an aspect, no violation of the PSR (or of "same cause, same effect") would obtain. Still, having no firm grasp of what Spinoza means by "expression" I can make this claim only in a very tentative manner.

I turn now to Martin Lin's comments on the last two chapters of the book. In these two chapters, I present an outline of Spinoza's metaphysics of thought and argue for three interrelated theses. (1) In chapter 5 I show that the celebrated Spinozistic doctrine commonly termed "the doctrine of parallelism" is in fact a conflation of two separate and independent doctrines of parallelism. Hence, I argue that our current understanding of Spinoza's metaphysics and philosophy of mind is fundamentally flawed.(2) The clarification and setting apart of the two parallelism doctrines puts us in a position to address one of the deepest and most enduring problems in Spinoza's metaphysics: How can the attribute of Thought be isomorphic with any other attribute, and yet also with God himself, who has infinitely many attributes? In chapter 6, I argue that the number and order of modes is the same in all attributes. Yet modes of Thought, unlike modes of any other attribute, have an infinitely-faceted structure, so that one and the same idea represents distinctly the infinitely many modes by having infinitely many aspects. (3) This new understanding of the structure of ideas in Spinoza allows us to solve another old riddle in Spinoza's metaphysics: his insistence that it is impossible for the human mind to know any of God's infinitely many attributes other than Thought and Extension. I show that for Spinoza ideas (or minds) of modes belonging to different attributes cannot communicate with each other, just as their ideata cannot communicate with each other.

These two chapters are admittedly not an easy read, and the detailed arguments in them demand close scrutiny. Lin raises a number of important issues with regard to both method and content, and I am very grateful to him for his insightful comments. I will begin with issues of method.

\$9. Method. - Lin attributes to me a method of rational reconstruction that attempts to find a deeper, consistent meaning beneath the problematic surface of the text. Lin clearly appreciates this attitude, yet suggests an alternative: "My own view is that such extrapolations are interesting mainly because they show along what lines the explicit ideas of the philosopher being interpreted might be developed and

The Leibniz Review, Vol. 23, 2013 
not because they reveal the underlying philosophy. I normally assume that if an author has not written in detail about a given topic, it is because he or she has not thought about that topic in detail" [195]. While I am sympathetic to some types of rational reconstruction (as for example, in the works of Martial Gueroult), I have to admit that I also agree with Lin's claims, and indeed much of my work in these two chapters is dedicated to a close reading of Spinoza's text for the purpose of documenting my claims. Did Spinoza write in detail about the minds of modes belonging to attributes other than Extension? No, because he did not think he knew much about these minds, and because his focus in parts 2-5 of the Ethics was on the human mind and its salvation (as the preface to part 2 makes clear). Knowledge of the modes of the unknown attributes seems be of little relevance to the salvation of the human mind, and therefore Spinoza's remarks on this issue are rather scattered. Yet, we have plenty of texts - in the Short Treatise, the correspondence, and the Ethics - indicating that modes of the other attributes also have minds, and I see no reason to disregard these texts.

§10. Could We All Miss This? - Lin writes: "Stubborn apparent inconsistencies that generations of interpreters have not succeeding in resolving (at least not uncontroversially) are generally real inconsistencies" [195]. Clearly, Lin makes this claim as a word of caution, rather than as a ban on radical new interpretations, and I think that such caution is in order. The theses I develop in chapters 5 and 6 are bold, and if I am right, it seems that a significant part of the core of Spinoza's philosophy has been poorly understood for three centuries. Lin is right that bold theses such as mine demand strong documentation. The reader is invited to read the two chapters and judge for herself to what extent my claims are documented in Spinoza's text. Yet I would also like to point out two factors which might help explain the persistence of the problem. First, the introduction of the term "parallelism" - sometime in the mid nineteenth century ${ }^{14}$ - contributed significantly to the conflation of E2p7 and E2p7s, since both texts could be aptly said to describe parallelism, though, as I argue, they describe distinct kinds of parallelism, and distinct doctrines. In the past century and a half, the term 'parallelism' has been so common in circles of Spinoza scholarship that one might assume it was frequently employed by Spinoza himself (though he never used it at all). Second, I should note that I am definitely not the first to point out discrepancies between E2p7 and E2p 7s. That the two texts make distinct claims is well noted in the existing literature. ${ }^{15}$ Previous scholars have tended to assume that one doctrine is derivable from the other. I have shown, I believe, that the two doctrines are conceptually independent

The Leibniz, Review, Vol. 23, 2013

\section{5}


of one another, i.e., that neither implies the other.

11. What Is a Scholium? - In my fifth chapter, I argued that in E2p7 (and its demonstration and corollary) Spinoza attempts to establish one doctrine - the IdeasThings Parallelism - while the scholium to E2p7 addresses the related but distinct doctrine of the Inter-Attributes Parallelism. Addressing this issue, Lin writes: "Is it plausible to think that Spinoza intended to express two distinct parallelism doctrines in $2 \mathrm{p} 7,2 \mathrm{p} 7 \mathrm{~d}, 2 \mathrm{p} 7 \mathrm{c}$ and $2 \mathrm{p} 7 \mathrm{~s}$ ? If he did, then he expressed himself very poorly indeed since none of his readers, from the seventeenth century until Melamed, have suspected him of doing so" [198]. I do not have access to the minds of Spinoza's contemporaries, but I am not aware of a text by any of them showing that they treated E2p7 and E2p7s as expressing the same doctrine. As I mentioned in my previous note, the misleading and conflating title of "parallelism" was introduced long after they were all dead. Yet, the distinction between E2p7 and E2p7s is well documented and common in the existing literature, as I just pointed out. Still, the question remains: Why would Spinoza attach a scholium discussing the InterAttributes Parallelism to E2p7, which argues for the Ideas-Things Parallelism? To answer this question, let's first remind ourselves of what a scholium is and how is it distinct from a corollary. A corollary, in the Ethics, infers a further conclusion from the proposition proved. This is not the role of the scholium, which is rather a certain study or remark, limited in scope, that is related to the topic of the proposition, or sometimes even to a group of recent propositions. Thus, for example, the two scholia after E1p8 primarily address issues related to E1p7. This is a standard practice for Spinoza, well documented by previous studies. ${ }^{16}$ At this point, one may ask: How are E2p7 and E2p7s related? Well, both assert parallelism between Thought items and non-Thought items, and both entail the mind-body parallelism. This seems to perfectly justify reminding the reader about one doctrine (in E2p7s) following the conclusion of the discussion of the other (E2p7). Notice, though, that the two parallelisms have different features: specifically, the Inter-Attributes Parallelism involves identity among parallel items, while the Ideas-Things Parallelism does not involve identity. This feature allows us to check the extent to which Spinoza made a clear distinction between the two doctrines in the later parts of the book. Going over all the propositions in the Ethics that refer to E2p7 or E2p7s in their demonstrations, I found not even a single example in which Spinoza conflates the two, i.e., he never refers to E2p7 in order to make an identity claim. ${ }^{17}$ Finally, let me point out that, on the basis of their subject matter, the two parallelism doctrines belong to different parts of the Ethics. The Inter-Attributes Parallelism does not

The Leibniz Review, Vol. 23, 2013 
belong to part 2 of the Ethics, whose subject is the human mind. Rather, it belongs to the very heart of Spinoza's ontology, and as I have shown, ${ }^{18}$ it was proved as early as E1p16 (which is indeed the heart of Spinoza's ontology); E2p7s only reminds the reader of it.

\$12. Branching. - Lin raises an interesting objection, by suggesting a scenario in which the effects of God's essence (i.e., the infinite modes) branch and, as a result, disrupt the order of the Ideas-Things Parallelism [200-201]. In my chapter on the infinite modes, I argued that according to E1p21d and E1p22d there is only one infinite mode per degree of mediation. ${ }^{19}$ This issue also comes up in my response to Marshall ( $\S 8$ above). Thus, the scenario suggested by Lin does not obtain. However, I do recognize a closely related problem: the existence of a onestep lag between the two parallelisms (a lag which is restricted to the domain of the infinite modes). ${ }^{20}$ This problem does not result from my interpretation, but is rather shared by all interpreters who hold that God's idea is a mode, and therefore cannot be identical to God (since a mode cannot be identical to a substance). ${ }^{21}$

\$13. Idea-Aspects. - In my sixth chapter I argued that each idea in God's intellect represents distinctly the parallel infinitely many modes (belonging to the infinitely many attributes) by virtue of having infinitely many idea-aspects. Thus, for example, my mind is just an idea-aspect representing my body, while the mode of the third attribute parallel to my body is represented by another idea-aspect of the very same idea. Lin is quite sympathetic to this reading, yet he wonders what aspects are. How are they distinguished from modes? And why assume the existence of such a category of entities, which Spinoza never mentions? [203]. I will answer these questions in reverse order. First, 'idea-aspect' is indeed a term not used by Spinoza. The word 'aspect' was not even coined in the English of his time. Were I to use precisely the terms employed by Spinoza, I should perhaps have referred to minds, since in Letter 66, Spinoza writes that the mental representations of parallel modes "cannot constitute one and the same mind [mens]." Since the term 'mind' has a very different meaning in our vocabulary, I thought such a use was likely to generate confusion, which I preferred to avoid. For that reason, I decided to employ the term 'aspect', which in its common use (today) connotes quite aptly the relation Spinoza refers to. Let me stress, however, that aspects do not constitute a distinct ontological category, but rather a functional term. Being an aspect is the relation which holds between an entity under one attribute and the same entity under the infinitely many attributes. In the context of the substance, each attribute is an aspect of the substance. In the context of ideas, each idea-aspect is an aspect

The Leibniz, Review, Vol. 23, 2013 
of one and the same idea. Thus, the idea representing God (a substance of infinitely many attributes) has infinitely many aspects, each of which represents an aspect of God, i.e., God under a specific attribute. In the introduction to the book, I hinted at a new interpretation of Spinoza's attributes qua aspects of God. I further develop this reading in a forthcoming piece. ${ }^{22}$

\$14. Infinitely Many Attributes As a Misstep? - Lin aptly notes that my interpretation is (partly) motivated by the need to provide a coherent explanation for Spinoza's claims about the existence of infinitely many attributes unknown to the human mind. Since Thought is supposed to represent distinctly all the infinitely many attributes, it must have a far more complex structure than the other attributes; the claim that each idea represents its infinitely many parallel modes by having infinitely many idea-aspects thus provides an explanation of the unique complexity of Thought. Diagnosing Spinoza's claims about the infinitely many unknown attributes as the source of the problem, Lin suggests an alternative solution: "What are we to make of the doctrine of infinite unknown attributes itself? There is no doubt that Spinoza held it and that it was important to him. He asserts it again and again, even in the face of tough criticism from Tschirnhaus. I think, nevertheless, Spinoza's reasons for believing it are weak. First of all, he simply defines God as a substance with infinitely many attributes (1d6). But what motivates this definition? The underlying justification seems to be the thought expressed in 1p9: the more reality something has the more attributes it has. God is the most real being. Therefore, God has infinitely many attributes. But the conclusion does not follow from the premises. The most we ought to conclude is that God has every possible attribute. It does not appear that this line of reasoning could tell us how many possible attributes there are. It does not appear, therefore, that Spinoza had good reasons for believing the doctrine of God's infinite unknown attributes... Given that Spinoza doesn't need the doctrine, it seems permissible to acknowledge that Spinoza holds it, but then politely ignore it for the purpose of understanding and preserving the rest of Spinoza's system. This is my preferred option and it reflects the methodological assumptions I articulated at the beginning of this review" [203204].

A view similar to Lin's has been argued by Jonathan Bennett, though Bennett, unlike Lin, holds that there is hardly any evidence in Spinoza's texts to show that he believed that God has more than two attributes. ${ }^{23}$ Bennett's claim is false,${ }^{24}$ and Lin should be commended for avoiding it. Still, several weighty considerations tell even against Lin's more nuanced view. First, even though I agree with Lin that at

The Leibniz, Review, Vol. 23, 2013 
present we do not have a good understanding of E1p9 (and generally of what Spinoza means by reality), this proposition (and its discussion in E1p10s1) makes clear that for Spinoza God must be more real than anything else, and thus must have more attributes than anything else. Thus, it seems to be agreed that, according to E1p9, God must have at least three attributes (since you and I each exist in two attributes and God is more real than either of us). Once one admits that God, or Nature, has at least three attributes, the question of the extra-richness of Thought immediately arises in its full force and urgency. Thus, Lin's diagnosis of the problem seems to fail: the extra-richness of Thought is not the result of God's having infinitely many attributes.

Second, Lin argues that Spinoza fails to motivate his definition of God in E1d6. But this is not unique to E1d6. Does Spinoza provide us with explanations for his equally intriguing definitions of causa sui (E1d1) or attribute (E1d4)? From Spinoza's correspondence and the TdIE, we know that he considered an adequate definition to be one that captures the essence of the thing, ${ }^{25}$ and we may assume that E1d6, just like E1d1 and E1d4, does attempt to capture the essence of the thing defined. Yet, the norms of an axiomatic system are such that the definitions are not supposed to be motivated. ${ }^{26}$

Does Spinoza explain why each attribute of God must be infinite in its kind (E1d6)? He does not. Should we then "politely ignore it for the purpose of understanding and preserving the rest of Spinoza's system"? I do not believe that we should. Lin's important question does make me think that we should put the elucidation of Spinoza's notion of infinity quite high among our scholarly desiderata. However, I think we should avoid taming Spinoza, since Spinoza-sans-E1d6 (the definition of God) is not really Spinoza any more, but rather one of us, and we have plenty of ourselves all around. Make no mistake: it is not for the sake of historical accuracy that I make this claim. We should avoid domesticating past philosophers in order to gain more philosophical insights. Spinoza's notion of infinity - precisely because of its foreignness to us - is capable of challenging our deepest-seated convictions. What more can one expect from good philosophy?

In closing, let me again thank Lin and Marshall for their insightful and productive comments. It is precisely such rich and generous critiques which help us make progress by better understanding our own views, and our blind spots. I look forward to continuing this conversation in the years to come.

The Leibniz, Review, Vol. 23, 2013 
Yitzhak Y. Melamed

Professor

Department of Philosophy

Johns Hopkins University

281 Gilman Hall

3400 N. Charles Street

Baltimore, MD 21218

ymelame1@jhu.edu

\section{References}

Bennett, Jonathan (1984). A Study of Spinoza's Ethics. Indianapolis: Hackett.

Curley, Edwin (1969). Spinoza's Metaphysics: An Essay in Interpretation. Cambridge, Mass.: Harvard University Press.

Della Rocca, Michael (1996). Representation and the Mind-Body Problem in Spinoza. Oxford: Oxford University Press.

Hegel, G.W.F. (1995). Lectures on the History of Philosophy. 3 volumes. Translated by E.S. Haldane and F.H. Simson. Lincoln: University of Nebraska Press. Hume, David (2000). A Treatise of Human Nature. Edited by David Fate Norton and Mary J. Norton. Oxford: Oxford University Press.

Melamed, Yitzhak Y. (2013). Spinoza's Metaphysics: Substance and Thought. Oxford: Oxford University Press.

(forthcoming). "The Building Blocks of Spinoza's Metaphysics: Substance, Attributes, and Modes.” In The Oxford Handbook of Spinoza, edited by Michael Della Rocca. Oxford: Oxford University Press.

Spinoza, Benedict (1925). Opera. 4 volumes. Edited by Carl Gebhardt. Heidelberg: Carl Winter Verlag. (1985). The Collected Works of Spinoza. Vol. 1. Edited and translated by Edwin

Curley. Princeton: Princeton University Press.

(2002). Complete Works. Translated by Samuel Shirley. Indianapolis: Hackett.

\section{Notes}

${ }^{1}$ See Curley [1969], chapters 1-2. Unless otherwise marked, all references to the Ethics, the early works of Spinoza, and Letters 1-29 are to Curley's translation: The Collected Works of Spinoza, vol. 1. In references to the other letters of Spi- 
noza I have used Shirley's translation: Spinoza, Complete Works. I have relied on Gebhardt's critical edition for the Latin text of Spinoza. I use the following standard abbreviations for Spinoza's works: TdIE - Treatise on the Emendation of the Intellect [Tractatus de Intellectus Emendatione], DPP - Descartes' Principles of Philosophy [Renati des Cartes Principiorum Philosophiae Pars I \& II], CM - Metaphysical Thoughts [Cogitata Metaphysica], KV - Short Treatise on God, Man, and his Well-Being [Korte Verhandeling van God de Mensch en deszelfs Welstand], TTP-Theological-Political Treatise [Tractatus Theologico-Politicus], Ep. - Letters. Passages in the Ethics will be referred to by means of the following abbreviations: a(-xiom), c(-orollary), p(-roposition), s(-cholium) and app(-endix); 'd' stands for 'definition' when it appears immediately to the right of the part of the book, and to 'demonstration' in all other cases. Hence, E1d3 is the third definition of part 1 and E1p16d is the demonstration of proposition 16 of part 1. I would like to thank Nick Kauffman, Colin Marshall and Oded Schechter for their comments on earlier versions of this paper.

${ }^{2}$ KV I, iii I I/35/19.

${ }^{3}$ Furthermore, in Ep. 60 Spinoza does not shy away from insinuating that even the causa sui is a genuine efficient cause. In this text, Spinoza states that a proper definition of God must refer to God's efficient cause, thus making it clear that God has an efficient cause.

${ }^{4}$ Instead, Spinoza would say that God's existence is an eternal truth (TIE §54, note u) (i.e., that God's essence implies his existence), or that "God's decisions and volitions are eternal truths" (TTP, ch. 4. I III/55). In both cases, God himself is not identified with an eternal truth.

${ }^{5}$ Hegel [1995], 3:269. Cf. page 273 in the same volume, where Hegel complains that in Spinoza individuality "is not deduced, it is found."

${ }^{6}$ Hegel might show how the category of individuality is developed or "deduced," but such an unfolding of categories is relegated by Spinoza to the study of human psychology, and does not belong to the core of his ontology.

${ }^{7}$ I am indebted to John Brandau for pointing out that Hegel did not derive individuals from his absolute either.

${ }^{8}$ As a side note, let me add that, unlike Descartes, who asserts that errors may come "from nothing" (Discourse, Part IV I AT VI 34), Spinoza seems to hold that errors and illusions are fully explainable through their causes.

${ }^{9}$ Ep. 32 I IV/169-70.

${ }^{10}$ Nor can the causal relation among the parts of $\mathrm{M}$ be an instantiation of an in se

The Leibniz Review, Vol. 23, 2013 
inherence, since the parts of $\mathrm{M}$ are distinct.

${ }^{11}$ The relevant passage in E1p21d is II/65/26-29: "Ergo per cogitationem, quatenus ideam Dei non constituit, quae tamen (per Prop. 11.) necessario existere debet. Datur igitur cogitatio non constituens ideam Dei, ac propterea ex ejus natura, quatenus est absoluta cogitatio, non sequitur necessario idea Dei. (Concipitur enim ideam Dei constituens, et non constituens)."

${ }^{12}$ Hume, Treatise of Human Nature, 1.3.15.6.

${ }^{13}$ I consider the infinite modes (not only the finite modes) to be divisible.

${ }^{14}$ See Melamed [2013], 144n9.

${ }^{15}$ Gueroult, Deleuze, and Bennett are just few of the scholars who have noted this. For precise references, see Melamed [2013], 140n2.

${ }^{16}$ See, for example, Della Rocca [1996], 115, on the relation between E2p35 and E2p35s.

${ }^{17}$ See Melamed [2013], 146.

${ }^{18}$ Melamed [2013], 146-151.

${ }^{19}$ Melamed [2013], 116-119.

${ }^{20}$ Melamed [2013], 188n74.

${ }^{21}$ See Melamed [2013], 144-145 and 187-188.

${ }^{22}$ See the section on the attributes in Melamed (forthcoming).

${ }^{23}$ Bennett [1981], 77-78.

${ }^{24}$ For detailed textual evidence, see the section on the attributes in Melamed (forthcoming).

${ }^{25}$ See TdIE $\$ 95$, CM I, i (I/234/26), Ep. 9 (IV/42/30), and Ep. 34.

26 Thus, Spinoza's very brief explanation in E1p10s 1 of the motivation for his definition of God is a rare exception. 